\title{
Development of Anti-theft Steering Wheel lock Embedded with Fingerprint System
}

\author{
Norzalina bt Othman, Nurul Na'imy Wan, Nik Nur Alyani Mohd Alwi, Pranesh Krishnan
}

\begin{abstract}
Development of Anti-theft Steering Wheel Lock Embedded with Fingerprint System is the new improvement from the current design which being upgraded by using the fingerprint sensor as the input. This fingerprint sensor is to secure only authorized user can access it and unlock the steering wheel lock. Otherwise, if the unauthorized user accesses the fingerprint sensor, the magnetic lock remains closed. The objective of this project is to develop an anti-theft steering wheel lock with fingerprint system by using Arduino Nano as a controller to reduce vehicle crime instead of using keys and code number. As stated, Arduino Nano was used as a microcontroller and steering wheel lock as the main component. The other ingredients are including $5 \mathrm{~V}$ relay, magnetic latch, and power supply. This project is expected to work well and active with the redesign.
\end{abstract}

Keywords: Anti-theft steering wheel lock, fingerprint sensor.

\section{INTRODUCTION}

$\mathrm{T}_{\mathrm{h}}$ hese days, the fitting of security devices to the vehicles has turned into an essential way to deal with the anticipation of the vehicle crime. According to U.K Home Office, Police Research Group, in automotive the manufacturers have concentrated basically on enhancing the security to forestall breaking-in to the vehicle and introducing devices to keep parked vehicles from being unlawfully driven away. [1] The development of Anti-theft Steering Wheel Lock Embedded with Fingerprint System is desirable because it can increase the security level to secure the steering wheel when the vehicle parked. It was programmed to open only when the correct access fingerprint was entered. The output signal is

Revised Manuscript Received on July 22, 2019.

* Correspondence Author

Norzalina bt Othman*, Malaysian Spanish Institute Universiti Kuala Lumpur, Kulim Hi-Tech Park, 09000, Kulim, Kedah. Email: norzalina@unikl.edu.my

Nurul Na'imy Wan, Head of Technical Foundation Section, Universiti Kuala Lumpur Malaysian Spanish Institute, Kulim Hi-Tech Park, 09000 , Kulim, Kedah. Email: nurulnaimy@unikl.edu.my

Nik Nur Alyani Mohd Alwi, Student, Bachelor of Engineering (Hons), Mechatronics (Automotive), Malaysian Spanish Institute Universiti Kuala Lumpur, Kulim Hi-Tech Park, 09000, Kulim, Kedah. Email: niknuralyanimohdalwi@gmail.com

Pranesh Krishnan, Intelligent Automotive Systems Research Cluster, Electrical Electronic and Automation Section, Malaysian Spanish Institute Universiti Kuala Lumpur, Kulim Hi-Tech Park, 09000, Kulim, Kedah. Email: pranesh@unikl.edu.my

(C) The Authors. Published by Blue Eyes Intelligence Engineering and Sciences Publication (BEIESP). This is an open access article under the CC BY-NC-ND license (http://creativecommons.org/licenses/by-nc-nd/4.0/) sent to the magnetic lock, and the lock opens automatically.

A lock is a mechanical or electronic fastening device that is released by a physical object such as key, key card, fingerprint, Radiofrequency Identification (RFID) card, or others. Each of the locks has its benefits and features. Here and now, an anti-theft steering wheel lock provided with key design and PIN coded system. The key design gives the user the fastest way to unlock the device compared to the Personal Identification Number (PIN) encrypted, and the key itself is impossible to duplicate by the third party unless with the help of manufactures. Whereas, PIN coded system can be set up to 10000 of combination and no keys required to lock and unlock the device. Even though both methods give the users essential benefits, unfortunately, people tend to misplace and forget the things when in a hectic situation.

In history, a PIN started with the introduction of the ATM in 1967, as a productive way for banks to dispense money to their clients. [3] Nowadays, the PIN code is the least complicated technique used to access system or open the locking entryways. The advantage of utilizing a PIN code is that it is not necessary to issue separate passes which wipe out the issues of tear or loss of keys. Nonetheless, this method has disservices as the users may forget the PIN code, and they cannot pass through the system quickly. For example, a user presents a credit/debit card for payment and enters a PIN to complete the transaction. If the user enters an invalid PIN, the user is allowed a limited number of authentication attempts.

Meanwhile, the barcode is a machine-intelligible code as numbers and a group of parallel lines with fluctuating width and spacing which is utilized for recognizing an item. Access cards with a scanner tag or a barcode are a decent decision for guest administration where the user accommodation is foremost [4]. The cards accessible at a reasonable expense, and it tends to be printed effortlessly. Other than that, the visitor is never again required to hand in the card since the approval applies temporarily. However, access cards are not appropriate for conditions where strict security necessities apply because the cards are accessible can be duplicate. The first generation of RFID tags was used in the 1950s for a military reason, yet it was limited to an identification reason. RFID uses electromagnetic fields to identify and track tags attached to objects. The tags contain electronically stored information. Passive tags collect energy from a nearby RFID reader's interrogating radio waves. Active tags have a local power source such as a battery and may operate at hundreds of meters from the RFID reader. Unlike a barcode, the tag need not be within the line of sight of the reader so that it may be embedded in the tracked object.

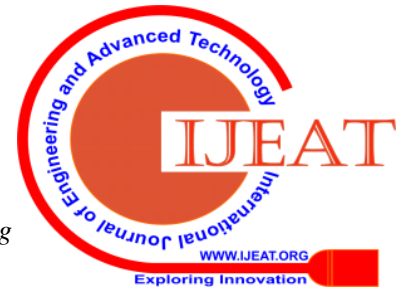




\section{Development of Anti-theft Steering Wheel lock Embedded with Fingerprint System}

RFID is one method for Automatic Identification and Data Capture (AIDC) [5].

In the case of biometric identification, the system recognizes a person automatically from a list of users in a database [6]. Biometrics is a strategy for setting up of confirming the identity of a person based on physical attributes.

Biometric verification is additionally conceivable for a situation of proving or preventing the identity of a person who, for example, exhibits an ID card. The individual can be prompted for a fingerprint to affirm the user identity. It has turned out to be one of the prominent and trustable security systems that have turned into an option to password-based security system [7].

Here and now, an anti-theft steering wheel lock provided with key design and PIN coded system. The key design gives the user the fastest way to unlock the device compared to the PIN coded and the key itself is kind of impossible to duplicate by the third party unless with the help of manufactures. Whereas, PIN coded system can be set up to 10000 of combination and no keys required to lock and unlock the device. Even though both methods give the users essential benefits, unfortunately, people tend to misplace and forget the things when in a hectic situation. Therefore, by improving the steering wheel lock with a biometric fingerprint sensor as the input, it helped the users to surpass the existing weakness.

Steering Wheel Lock these days is utilized in day by day life and have been part for the vehicle users; however, there is no perfect steering wheel lock in the world. Therefore, there are several probabilities to the professional thieve to bypass the current design by various mean include sawing the steering, cutting the wires and deceiving manufacturers to make a replacement key of the device. With such a large number of choices to hack the vehicles, The Federal Bureau of Investigation (FBI) Uniform Crime Reports (UCR) express that the number of vehicles got stolen every year varied around 1,200,000 from 1997 to 2006 in the urban city. [2]

The main objective of this project is to develop an anti-theft steering wheel lock with fingerprint system by using Arduino Nano as a controller to reduce vehicle crime. Besides, to attach the magnetic lock on the device to lock and unlock the steering wheel lock bar.

According to the research, Arduino Nano is identified to be suitable microcontroller for this project due to the size area to be fit on the steering wheel lock bar. Moreover, the type of steering wheel lock bar selected to be used is a baseball bat based steering wheel lock due to their method to open up the device and able to install magnetic lock fail secure. Other than that, this project proposed for developing a firmware code for steering wheel lock by adding a user-friendly interface to enroll, verify, delete, and detect an authorized user. The Adafruit Fingerprint Library is added on to the Arduino IDE to be program and while through the sensor, three samples of fingerprints are stored in the system to test and prove the project is working well.

\section{METHODOLOGY}

The security system design comprises of two parts which are the hardware and the software. The hardware implementation is done by designing and research for the circuit, including the selection of components. For the software part, the program codes are created based on the type of the microcontroller, and the programming Arduino used.

\section{A. Block diagram}

Based on Figure 3, the input is the fingerprint sensor itself. The users must enter the correct fingerprints that have been registered to access through the system. Once the right fingerprint is given, the data is sent to Arduino Nano to be processed. The controller transmits the signal to the $5 \mathrm{~V}$ relay. The relay then activates and cuts off the circuit so that no current is passed and the device is unlocked.

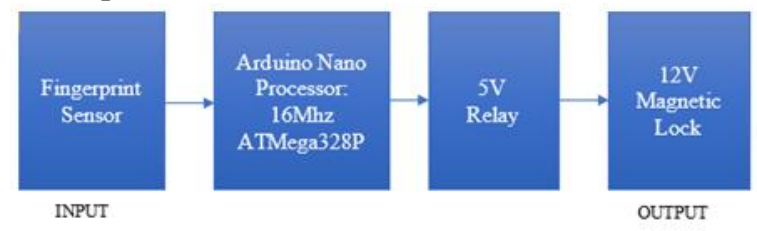

Fig. 1. Block diagram

\section{B. Flow Chart}

The system starts by entering correct fingerprints that have been registered into the system. When the right fingerprint is introduced, the Liquid Crystal Display (LCD) shows "Access Granted" and sends the signal to relay. It opens the magnetic lock since there is no current flow. Otherwise, if the wrong fingerprint was entered, the LCD shows "Access Denied," and the magnetic lock safely remains locked. The process ends so the user must enter correct fingerprint again to start the operation of the system.

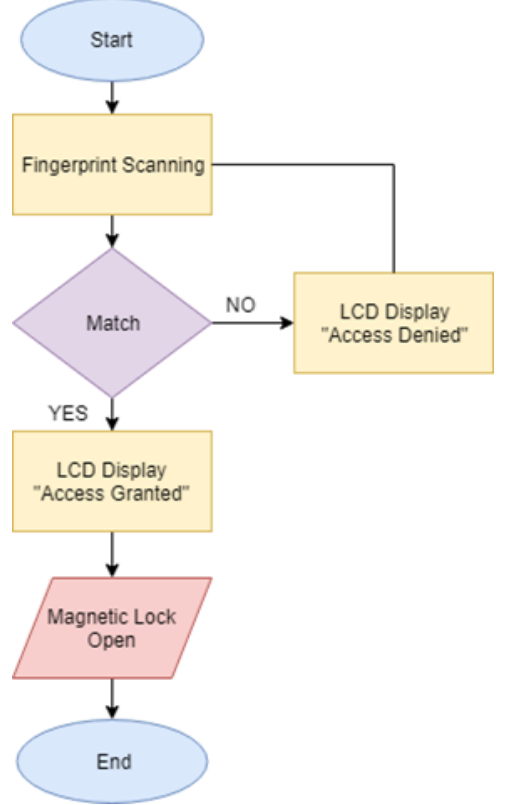

Fig. 2. Flow chart operations

\section{The method of the project}

Figure 5 shows the original design of the Baseball Bat Steering Wheel Lock. This type is selected to be the best component due to the method of opening the device (popping up/down). These days, most of the current steering wheel lock designed to be turned, pushed or pulled as the user unlock and lock the device. Hence, it quite hard to install the magnetic lock later on.

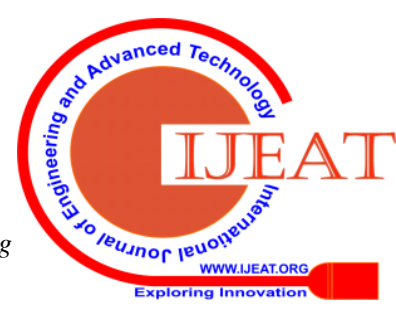


The critical area of Baseball Bat Steering Wheel Lock has a flat surface by using a cutting tool and replaced it with a magnetic lock fail secure. Since the steering wheel lock is made up by a mixture of aluminum, thus, the device had to add with the metal block before it can be able to weld. Meanwhile, on the top of the steering wheel lock, the circuit box of fingerprint sensor located soon.
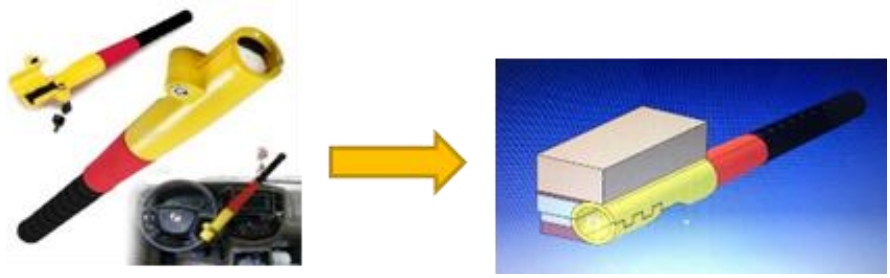

Fig. 3. The Original Looks of Baseball Bat Steering Wheel Lock and The Output Idea for Baseball Bat Steering Wheel Lock

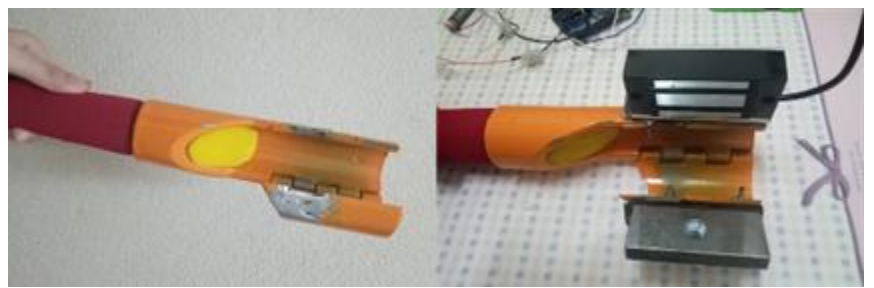

Fig. 4. Baseball Bat Steering Wheel Lock After Grinding and Welding

The mechanical drawing for the circuit box as in Figure 7. Rapid prototyping is used to produce it as a product by using material of Polylactic Acid (PLA). Rapid prototyping is a method of quickly creating a scale model of a part or finished product using computer-aided design (CAD) software. While, PLA is one of the most popular bioplastics, used for many applications ranging from a plastic box, Figure 8 to medical implants. Several of the holes are made to place the components (LCD and fingerprint sensor) and the power supply's wires.

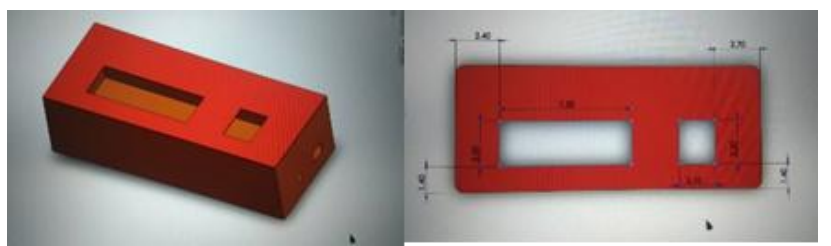

Fig 5. The Circuit Box with solid works

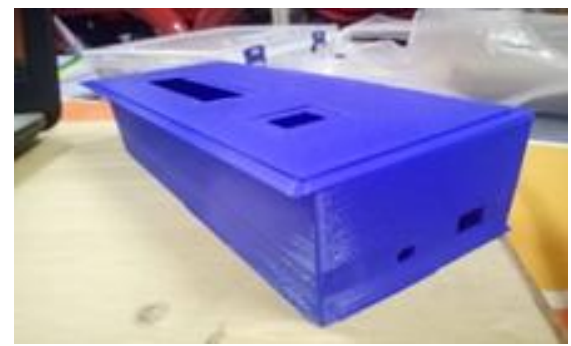

Fig 6. The Circuit Box with PLA Material

\section{RESULT AND DISCUSSION}

The process that has been completed and required to determine the performance and achievement of the project.
The picture below shows the result of the project which is control by the fingerprint system and magnetic lock fail secure as an input and output respectively.

\section{A. Project Overview}

In this project, there are two circuits; namely, the fingerprint sensor circuit and the magnetic lock circuit had been merged. Figure 11 shows the result of this project. As the LCD displayed the status of authorized users, the magnetic lock activated to unlock the baseball bat based steering wheel lock. The 5V relay produced a 'clicking' sound when received enough power supply from Arduino Nano and cut off the circuit so that no current passes through the magnetic lock and the device opened.

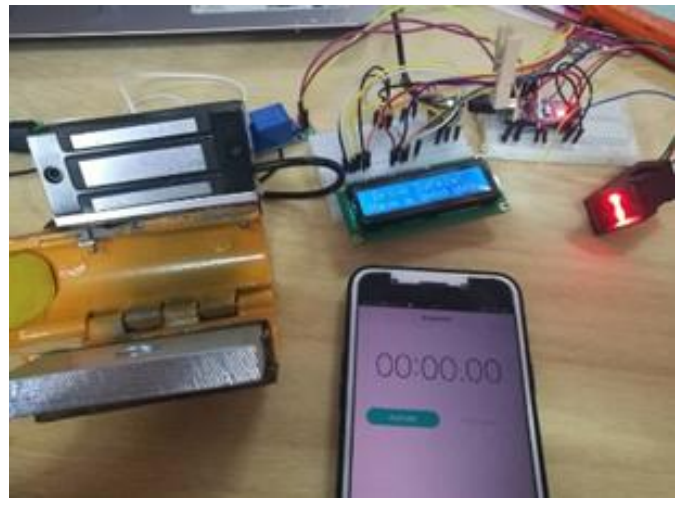

Fig. 7. The magnetic lock opened

\section{B. Analysis time is taken to unlock}

Initially, there are six fingerprint ID stored with two different users which ID\#1 until ID\#3 is user A, and ID\#4 until ID\#6 is user B, to be tested. The time taken to unlock the magnetic lock is recorded to determine how significant each fingerprint ID and temperature affected the system. This experiment is conducted three times per day for five days to record the time taken for every fingerprint ID. In this experiment, three times are selected, one in the morning $\left(10.00 \mathrm{am}\right.$ at $\left.30^{\circ} \mathrm{C}\right)$, twice in the evening $\left(2.30 \mathrm{pm}\right.$ at $\left.37^{\circ} \mathrm{C}\right)$ and $\left(9.30 \mathrm{pm}\right.$ at $\left.29^{\circ} \mathrm{C}\right)$. The anti-theft steering wheel lock has been placed in vehicle for the whole time, and the data is collected. Figure 12 shows one of the line graphs, which is for ID number 1 (thumb) the information about the time taken to unlock the steering wheel lock. The charts are shown below as blue, red and yellow lines for $10.00 \mathrm{am}, 2.30 \mathrm{pm}$ and $9.30 \mathrm{pm}$ respectively. The details of the data as in Appendix. As can be seen from the graph, there were different trends for every day except for day one and day four that quite similar. The least time taken to unlock the system is about $1.65 \mathrm{~s}$ in day 2 $(10.00 \mathrm{am})$, and the most are $2.86 \mathrm{~s}$ in day 3 (9.30 pm). TIME(S) VS 5 DAYS FOR ID\#1

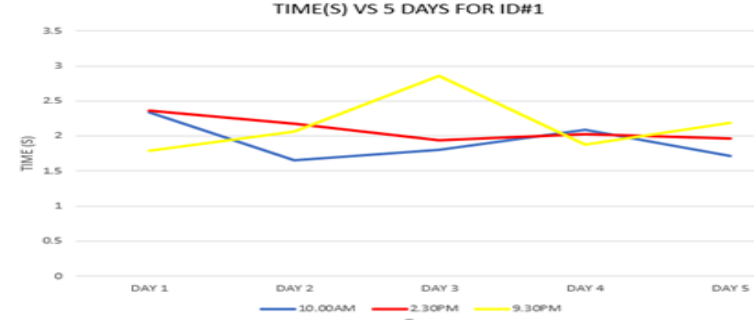

Fig 8. Line graph time(s) Vs. Days for an ID number

Published By:

Blue Eyes Intelligence Engineering \& Sciences Publication (C) Copyright: All rights reserved.

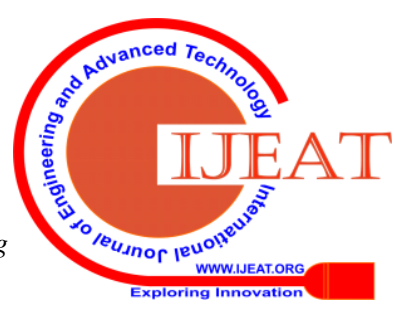




\section{Development of Anti-theft Steering Wheel lock Embedded with Fingerprint System}

Figure 13 shows the average for five days which is Average of Time(s) versus ID numbers. The graph plotted shows that the time taken for each of the lines is different from each other. It can be seen that the time is taken rise up from $2.38 \mathrm{~s}$ for ID\#2 and fell slightly to 2.09s for ID\#3 at $2.30 \mathrm{pm}$.

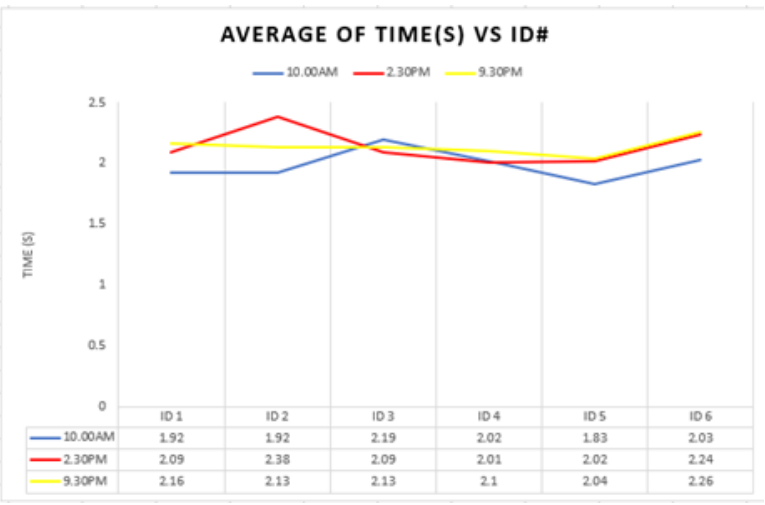

Fig 9. Line graph average of time (s)

The shortest time is taken to unlock the device after the fingerprint sensor access an authorized user is 1.83s for ID\#5 on average. However, it happens in the other way around for ID\#2 which takes 2.38s to unlock due to some factors which include the scanner unable to read the fingerprint correctly and the user slow in getting the fingerprint on the scanner. Overall, the duration to unlock the magnetic lock is less than 3s as the controller is programmed to unlock the device in $1000 \mathrm{~ms}$ or $1 \mathrm{~s}$.

\section{CONCLUSION}

This project has met its objectives. Firstly, it is to develop an anti-theft steering wheel lock with fingerprint system by using Arduino Nano as a controller to reduce vehicle crime. It has completed as the fingerprint sensor able to detect an authorized fingerprint on the scanner while the coding created by using Arduino IDE software. Other than that, it is to attach the magnetic lock on the device to lock and unlock the steering wheel lock bar. When the fingerprint sensor reads an authorized fingerprint, there is no current passing through the magnetic lock due to the cut off circuit from the relay. Thus, the magnetic lock unlocked. The results obtained were like the expected outcomes. In conclusion, all the objectives of this project are successfully achieved.

\section{ACKNOWLEDGMENT}

The authors express their deepest appreciation to Research and Innovation Section, Universiti Kuala Lumpur Malaysia Spanish Institute.

\section{REFERENCES}

1. Barry, W. (2000). Steering column locks and motor vehicle theft: evaluations from three countries. London, UK: Home Office Police Research Group.

2. Brooks, R.R., Sander, S. \& Juan, D. (2009). Challenges and state of the art of automotive system. IEEE Vehicular Technology Magazine. 53.

3. Brian, M. (2007). BBC News. The man who invested the cash machine.

4. Habtamu, A. (2006). Different Ways to Authenticate Users with the Pros and Cons of Each Method. Retrieved https://www.nr.no/directdownload/4380/AbieDifferent_Ways_to_Auth enticate_Users_with_the_Pros.pdf
5. Automatic Identification and Data Collection (AIDC) Archived May 5, 2016, at the Wayback Machine.

6. Syed, Z.S.I., Estelle, C., Christophe, R. \& Jean, J. S. (2013). A Review on Authentication Methods. Australian Journal of Basic and Applied Science. 95-107.

7. Brian, M. (2007). BBC News. The man who invested the cash machine.

\section{AUTHORS PROFILE}

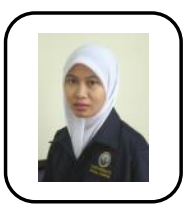

Norzalina Othman is working as Senior Lecturer with Universiti Kuala Lumpur Malaysian Spanish Institute. She completed her Master Science in Image Processing from Universite de La Rochelle, France. Her teaching experience is span over 17 years by teaching image processing and embedded programming courses. Her research interests include image processing, embedded programming and wireless optical communication. Email: norzalina@unikl.edu.my

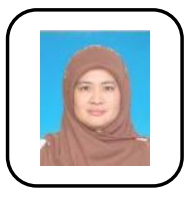

Nurul Na'imy Wan is working with Universiti Kuala Lumpur Malaysian Spanish Institute as Senior Lecturer. She completed her MSc. in Quality and Productivity Improvement from Universiti Kebangsaan Malaysia, Malaysia. Her research interests include structural equation modeling, service quality, and manufacturing process optimization and improvement. Email: nurulnaimy@unikl.edu.my

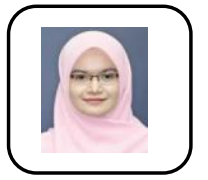

Nik Nur Alyani Mohd Alwi is an undergraduate student in Universiti Kuala Lumpur Malaysian Spanish Institute. She is a Final Year student of Bachelor of Engineering Technology (Hons.) in Mechatronics (Automotive).

Email: niknuralyanimohdalwi@gmail.com

Dr Pranesh Krishnan is working as a Post-Doctora Researcher. He completed his PhD and MS degrees at Universiti Malaysia Perlis, Malaysia. He has published over 25 articles in reputed conferences and high impact factor journals. His research interests include signal processing, machine learning, drowsiness research, and wearable sensors. Email: pranesh@unikl.edu.my

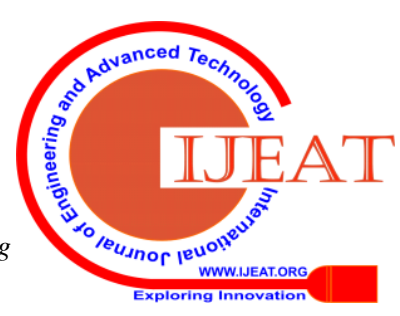

